\title{
DENGUE PREVENTION PRACTICES AND ITS DETERMINANTS FACTORS IN PURWOKERTO, CENTRAL JAVA
}

\author{
Sahida Woro Palupi ${ }^{1}$, Siwi Pramatama Mars Wijayanti ${ }^{2}$, Devi Octaviana ${ }^{2}$ \\ 1) Primary Health Care Kalipucang, Pangandaran, West Java \\ 2) Department of Public Health, Faculty of Health Sciences, Jenderal \\ Soedirman University, Purwokerto, Central Java
}

Corresponding author: Sahida Woro Palupi. Address: primary Health Care Kalipucang, Pengandaran, West Java, Email :

\begin{abstract}
Background Dengue Hemorrhagic Fever (DHF) is a disease transmitted through the bite of Aedes aegypti and Aedes albopictus that have been infected with the dengue virus. PSN DBD (DHF mosquito breeding areas elimination) is one of the most effective ways to prevent DHF. DHF is an endemic disease in Banyumas regency. This research aimed to analyze the factors that influence the behavior of PSN DHF in the East Purwokerto District, Banyumas Regency. Methods This research was quantitative research using a cross-sectional approach. The populations in this research were 17.289 households and the sample was housewives in East Purwokerto district taken by simple random sampling technique with 96 respondents. The data collection technique was carried out by using questionnaires and observation. Data analysis was conducted by univariate, bivariate, and multivariate.Results Education $(p=0,129)$, income $(p=0,170)$, knowledge $(p=0,254)$, attitude $(p=0,942)$, facilities availability $(p=0,130)$, role of community figures $(p=0,712)$ and role of health workers $(p=0,635)$ showed has no significant correlation with behaviour of PSN DHF. Information media exposure $(p=0,004)$ showed has significant correlation and the main factor of PSN DHF. Conclusions: Media exposure is the most influential variable in the behavior of PSN DHF. One of the advice given was to the health institution to should give more various ways of information related to dengue prevention in the community.
\end{abstract}

Keywords: Dengue, virus, prevention, mosquito

\section{INTRODUCTION}

Dengue Fever (DF) is an Arthropod-Borne Virus (Arbovirus) infection caused by Dengue Virus (DENV) and transmitted by the bite of Aedes aegypti and Aedes albopictus mosquitos. This disease occurs mainly in the tropics because it is associated with environmental factors such as temperature, humidity, and rainfall. However, DF is also found in some sub-tropical regions mainly due to the spread of Aedes albopictus mosquitoes which are more resistant to lower weather. In Indonesia, since it was first identified in 1968, DF cases continue to emerge in various provinces in the country. Incidence levels seem 
cyclic, peaking about every $6-8$ years. The case fatality rate has decreased by about half per decade, since 1980. Last year Java Island reported the largest total number of cases of dengue hemorrhagic fever [1]. Transmission of this disease is also influenced by several factors such as population mobility, demographics, temperature, humidity, and prevention efforts by the community [2].

Some prevention efforts are carried out such as the eradication of mosquito breeding sites which include closing and draining mosquito breeding places, as well as burying/disposing of used goods that have the potential to become mosquito breeding sites and minimize mosquito bites. The use of mosquito coils and household insecticides such as repellent to repel mosquito bites is also widely applied in the community. However, this disease continues to appear in various regions in Indonesia. This happened one of them due to a lack of prevention efforts made in the community. Prevention efforts that are carried out continuously and consistently seem difficult. It is interesting to study what factors influence prevention efforts undertaken by the community.

The previous study conducted in Malang, Indonesia showed that age, gender, number of family members, and perception of dengue susceptibility were associated with dengue prevention behavior [3]. Another study carried out in Malaysia suggested that dengue prevention should focus on messages highlighting the risk of contracting dengue and health education to improve knowledge and awareness on dengue [4]. Although there have been several previous studies, information about the factors that influence DF prevention behavior in the Banyumas district is still limited. Health behavior is usually strongly influenced by local customs and culture of a region. Prevention efforts of DF are also possibly influenced by the role of local regional leaders and also the role of health cadres. In Indonesia, there is a program called Jumantik "larva monitor" which is a community cadre whose job is to check the larvae of every house within its scope of work. In this study, we are interested in examining the factors that influence DF prevention behavior in the community. The results of this study are expected to provide input to health institutions related to programs to improve DF prevention behavior in the community.

\section{METHODS}

\section{Study design and Location of Study}

The research design was analytic research with a cross-sectional approach. The research location was in East Purwokerto Subdistrict, Banyumas Regency. The study population was 17,289 families in the East Purwokerto sub-district divided into 6 sub-districts. Determination of the number of samples carried out using the Minimum Sample Size formula obtained as many as 96 families. The proportional calculation is then carried out for each village, and sampling collection used a proportional simple random sampling technique. The areas of this study were Purwokerto Lor, Arcawinangun, Mersi, Kranji, Sokanegara, and Purwokerto Wetan, The inclusion criteria in this study were housewives who were willing to become respondents by signing informed consent. The exclusion criteria for conducting research were respondents who were away or had moved from the District of Purwokerto Timur.

\section{Data collection}


The independent variables consisting of education, income, knowledge, attitudes, facilities, information media exposure, the role of community leaders and health workers and the dependent variable is the behavior of DF prevention. The flow of research includes preparation, data collection, processing, and data analysis. The instruments used in this study are questionnaire, checklist, mechanical equipment. The validity of the questionnaire using the product-moment formula and reliability using the Cronbach's Alpha method.

\section{Data Analysis}

This study uses primary and secondary data. The analysis carried out in this study were: frequency distribution analysis, bivariate analysis using chi-square test, and multivariate analysis by logistic regression.

\section{RESULTS}

96 respondents housewives who were interviewed related to DF prevention efforts participated in this study. The characteristics and frequency distribution of several variables can be shown in Table 1.

Table 1. Characteristic and frequency distribution of variables

\begin{tabular}{|l|l|c|c|}
\hline Variables & Category & Frequency (n) & Percentage (\%) \\
\hline \multirow{5}{*}{ Education } & Uneducated & 2 & 2,1 \\
\cline { 2 - 3 } & $\begin{array}{l}\text { Basic educated (elementary school, } \\
\text { junior high school) }\end{array}$ & 49 \\
\cline { 2 - 3 } & Senior High School & 34 & 35,4 \\
\cline { 2 - 3 } & University & 11 & 11.5 \\
\hline Income & High (>IDR 1.350.000,- ) & 52.1 \\
\hline & Low (S IDR 1.350.000,-) & 47.9 \\
\hline Knowledge & Good & 46 & 65.6 \\
\hline & Bad & 63 & 34.4 \\
\hline Attitude & Supportive & 33 & 55.2 \\
\hline & Not supportive & 53 & 44.8 \\
\hline Facilities & Adequate & 43 & 50 \\
\hline & Not Adequate & 48 & 50 \\
\hline Exposure of media information & Good & 48 & 72,9 \\
\hline & Bad & 70 & 26 \\
\hline Role of community leader & Supportive & 59 & 27.1 \\
\hline & Not supportive & 37 & 61.5 \\
\hline Role of health workers & Supportive & 52 & 38.5 \\
\hline & Not supportive & 44 & 54.2 \\
\hline Practice of dengue prevention & Good & 64 & 45.8 \\
\hline & Bad & 32 & 66.7 \\
\hline
\end{tabular}

Based on the characteristics of the respondents, $51 \%$ of respondents had a basic education and only $11.5 \%$ took higher education at the university. While most of their knowledge $(65.6 \%)$ is in a good category, and $72.9 \%$ are also well exposed to the information media related to DF prevention. Their behavior in preventing DF is also $66.7 \%$ included in the good category. Then, bivariate analysis was carried out and the summary of results can be seen in Table 2 . 
Based on an analysis of the questionnaire, there are still $39.6 \%$ of respondents who think dengue is not a contagious disease. The respondent considers DF is not a contagious disease because its transmission is not direct (physical contact). As many as $60.4 \%$ of respondents thought that mosquito breeding site eradication was less effective to prevent dengue transmission than fogging and there were still $33.3 \%$ of respondents who thought that PSN was only carried out when a case occurred.

Then, the bivariate analysis also conducted to asses the correlation between independent and dependent variables.

Table 2. Bivariate analysis

\begin{tabular}{|l|l|l|l|}
\hline No & Variable & P-value & interpretation \\
\hline 1 & Education & 0,471 & Not correlated \\
\hline 2 & Income status & 0,170 & Not correlated \\
\hline 3 & Knowledge & 0,254 & Not correlated \\
\hline 4 & Attitude & 0,942 & Not correlated \\
\hline 5 & Facilities & 0,130 & Not correlated \\
\hline 6 & Exposure to media information & 0,004 & Not correlated \\
\hline 7 & Role of community leader & 0,712 & Not correlated \\
\hline 8 & Role of health workers & 0,635 & Correlated \\
\hline
\end{tabular}

Multivariate analysis also was conducted to determine the most influential factor correlated with dengue prevention (Table 3).

Table 3. Multivariate analysis

\begin{tabular}{|l|l|l|l|}
\hline Variables & SE & Sig. & Exp $(\beta)$ \\
\hline $\begin{array}{l}\text { Exposure of media } \\
\text { information }\end{array}$ & 0,499 & 0,003 & 4,519 \\
\hline Knowledge & 0,489 & 0,400 & 1,509 \\
\hline Attitude & 0,517 & 0,382 & 0,636 \\
\hline Facilities & 0,473 & 0,071 & 2,345 \\
\hline Role of community leader & 0,509 & 0,592 & 0,761 \\
\hline Role of health workers & 0,556 & 0,883 & 1,085 \\
\hline
\end{tabular}

The results of the logistic regression test showed that the most dominant influence on the behavior of dengue prevention is information media exposure $(p=0.003<0.05)$. An $\operatorname{Exp}(\beta)$ value of 4.519 implies that the exposure of information media to the behavior of dengue prevention increases 4.5 times greater to the behavior of good dengue prevention if followed by other variables than if not exposed to information media. This means that the exposure of existing information media can have a 4.5 times influence on the community in conducting dengue prevention properly

\section{DISCUSSION}

This study showed that media exposure is the most influential factor in dengue prevention behavior. Respondents who were exposed to information media mostly had good behavior than those who were not exposed to information media. The media information triggers change and influences people's lifestyles and behavior and becomes important in efforts to obtain new behaviors. Media information provides a 
message related to dengue prevention both through visual and audiovisual such as television, internet, social media, poster, and leaflet. These results supported the previous study in Thailand that showed a positive trend in the media information contribution in educating Thai people about dengue prevention [5]. In Malaysia, social media also found to be effective as a platform of interaction and spread the message about dengue prevention. The examples of social platforms that are highly used among users are Facebook and Twitter. This connection enhances the dissemination of information from users $[6,7]$.

However, in this study, we found that the respondents obtained information about DF prevention from others/neighbors (90.6\%). This could be related to the characteristic of respondents and local customs. Respondents in this study were the housewives, and their activity such as routine gathering with neighbors could create interaction between communities with various topics of conversation including dengue prevention. The activities of housewives such as recitation and social gathering can make information spread quickly. Other information media came from television (82.2\%) and posters $(61.5 \%)$, while the smallest frequency is $12.5 \%$ from internet sources. This is possible because housewives had less access to the internet in their daily lives. This local condition can cause the types of media that are mostly used by respondents to be different from other research studies.

In this study, the level of education, income, knowledge, attitudes, availability of facilities, the role of community leaders, and the role of health workers are not related to dengue prevention behavior. This is different from some previous studies which showed the role of community leaders and health workers $[8,9]$. The role of community leaders should provide examples, and information to the community to prevent dengue consistently. The community leader can be a village head, community leader or religious figure who is usually more respected by his recommendations. The role of health workers is also not related to this study. Their role of health workers should be very crucial to monitor dengue prevention efforts in community. The difference in the results of this study possibly because the research location is in an urban area where the characteristics of the population are more individual and there is no connection with community leaders. This is of course different from the characteristics of rural areas where the role of community leaders is very central. In the future, coordination between community leaders, health workers and the community must be carried out to encourage continued implementation of dengue prevention. Involvement of community to take active participation on dengue prevention appears to be successful. Community-based projects involving local authorities to help eradicate dengue mosquito breeding grounds are the only cost-effective and sustainable way of maintaining control in any dengue-affected country and resource-deficient countries $[10,11]$.

This research emphasizes the importance of information exposure from various sources in the community for the prevention of dengue. Well information exposure in the community will increase their knowledge and tend to be willing to actively participate in dengue prevention. Health institutions and related parties are expected to increase information exposure both visually and audiovisually in various ways to be effective and targeted. 


\section{ACKNOWLEDGMENTS}

\section{REFERENCES}

1. Harapan H, Michie A, Mudatsir M, Sasmono RT, Imrie A (2019) Epidemiology of dengue hemorrhagic fever in Indonesia: analysis of five decades data from the National Disease Surveillance. BMC Research Notes 12: 350.

2. Wijayanti SPM, Porphyre T, Chase-Topping M, Rainey SM, McFarlane M, et al. (2016) The Importance of Socio-Economic Versus Environmental Risk Factors for Reported Dengue Cases in Java, Indonesia. PLOS Neglected Tropical Diseases 10: e0004964.

3. Rakhmani AN, Limpanont Y, Kaewkungwal J, Okanurak K (2018) Factors associated with dengue prevention behaviour in Lowokwaru, Malang, Indonesia: a cross-sectional study. BMC Public Health 18: 619.

4. Wong LP, Shakir SMM, Atefi N, AbuBakar S (2015) Factors Affecting Dengue Prevention Practices: Nationwide Survey of the Malaysian Public. PLOS ONE 10: e0122890.

5. Boonchutima S, Kachentawa K, Limpavithayakul M, Prachansri A (2017) Longitudinal study of Thai people media exposure, knowledge, and behavior on dengue fever prevention and control. Journal of Infection and Public Health 10: 836-841.

6. Kannan R, Soon L, Govindasamy M (2019) Review on the Role of Social Media for Dengue Prevention and Monitoring. Applied Mechanics and Materials 892: 228-233.

7. Lwin MO, Vijaykumar S (2016) A Social Media mHealth Solution to Address the Needs of Dengue Prevention and Management in Sri Lanka. 18: e149.

8. Zahir A, Ullah A, Shah M, Mussawar A (2016) Community Participation, Dengue Fever Prevention and Control Practices in Swat, Pakistan. International journal of MCH and AIDS 5: 39-45.

9. Lin H, Liu T, Song T, Lin L, Xiao J, et al. (2016) Community Involvement in Dengue Outbreak Control: An Integrated Rigorous Intervention Strategy. PLOS Neglected Tropical Diseases 10: e0004919.

10. Asri, Nuntaboot K, Festi Wiliyanarti $P$ (2017) Community social capital on fighting dengue fever in suburban Surabaya, Indonesia: A qualitative study. International Journal of Nursing Sciences 4: 374-377.

11. Said MFF, Abdullah H, Abdul Ghafar N (2018) Dengue prevention practices among community in dengue hotspot area. 2018 5: 6. 